RUNNING HEAD: Parental age and DASS

Older maternal age is associated with depression, anxiety and stress symptoms in young adult female offspring

Jessica E. Tearne ${ }^{1,2}$, Monique Robinson ${ }^{1}$, Peter Jacoby ${ }^{1}$, Karina L. Allen ${ }^{2}$, Nadia K. Cunningham ${ }^{2}$, Jianghong $\mathrm{Li}^{3,1,4}$, Neil J. McLean ${ }^{2}$

${ }^{1}$ Telethon Kids Institute, The University of Western Australia, Perth, Australia

${ }^{2}$ School of Psychology, The University of Western Australia

${ }^{3}$ WZB Berlin Social Research Center, Germany

${ }^{4}$ Centre for Population Health Research, Faculty of Health Sciences, Curtin

University, Perth, Australia

Correspondence to:

Jessica Tearne

School of Psychology M304

The University of Western Australia

35 Stirling Hwy

CRAWLEY WA 6009

Email: jessica.tearne@research.uwa.edu.au

Phone: +618 64887189 


\begin{abstract}
The evidence regarding older parental age and incidence of mood disorder symptoms in offspring is limited, and that which exists is mixed. We sought to clarify these relationships using data from the Western Australian Pregnancy Cohort (Raine) Study. The Raine Study provided comprehensive data from 2900 pregnancies, resulting in 2868 live born children. 1220 participants completed the short form of the Depression Anxiety Stress Scale (DASS-21) at the 20 year cohort follow up. We used negative binomial regression analyses with log link and with adjustment for known perinatal risk factors to examine the extent to which maternal and paternal age at childbirth predicted continuous DASS-21 index scores. In the final multivariate models, a maternal age of 30-34 years was associated with significant increases in stress DASS-21 scores in female offspring relative to female offspring of 25-29 year old mothers. A maternal age of 35 years and over was associated with increased scores on all DASS-21 scales in female offspring. Our results indicate that older maternal age is associated with depression, anxiety and stress symptoms in young adult females. Further research into the mechanisms underpinning this relationship is needed.
\end{abstract}

Keywords: Raine Study, DASS, Cohort study, Maternal age, Paternal age

General Scientific Statement: This study suggests that older maternal age is associated with adverse symptoms of depression, anxiety, and distress in young adult females. Paternal age was not found to be associated with mental health outcomes for either males or females in this sample. 


\section{Older maternal age is associated with depression, anxiety and stress symptoms in young adult female offspring}

Both younger and older parental age has been linked to mental health problems in offspring. There is a substantial literature relating young parenthood, particularly teenaged motherhood, to adverse mental health outcomes in young children (Do et al., 1998; Fergusson \& Woodward, 1999; Harden et al., 2007; McGrath et al., 2014). Relative to offspring of older aged parents, offspring of teenaged mothers are at increased risk of mood disorders, internalising problems (e.g. withdrawal, depression/anxiety, somatic symptoms), substance misuse and juvenile crime (Fergusson \& Woodward, 1999; Harden et al., 2007). In terms of psychiatric diagnoses, offspring of teenaged mothers have been found to have a $51 \%$ increased risk of having any psychiatric diagnosis, and offspring of teenaged fathers a $28 \%$ increased risk (McGrath et al., 2014).

In the case of older parental age and offspring mental health problems, the research has focused overwhelmingly on psychiatric diagnoses. There is now strong evidence that the children of older fathers are at heightened risk of schizophrenia and autism spectrum disorders (Hultman, Sandin, Levine, Lichtenstein, \& Reichenberg, 2010; Miller et al., 2011), while the evidence for increased risk for bipolar disorder diagnosis is mixed with some studies suggesting a relationship (Frans et al., 2008; Menezes et al., 2010) and others finding no association (Buizer-Voskamp et al., 2011; McGrath et al., 2014). It has also been suggested that the effect of paternal age may be sexually dimorphic (Byrne, Agerbo, Ewald, Eaton, \& Mortensen, 2003; Miller et al., 2011). In the case of maternal age, advanced maternal age has been linked to increased risk for autism spectrum disorders (Sandin et al., 2012). Another study 
found that older maternal age increases risk for bipolar disorder diagnosis in offspring (Menezes et al., 2010), whereas other studies do not support this relationship (Frans et al., 2008; McGrath et al., 2014).

There is less information on the relationship between parental age and other mood disorders such as depression and anxiety. One large scale study using data from a Dutch population registry found adult offspring of both younger $(<20)$ and older $(\geq$ 40) fathers had significantly increased odds of a major depressive disorder diagnosis (Buizer-Voskamp et al., 2011). Similarly, relative to offspring of 25-29 year old parents, the adult offspring of teenaged mothers and fathers, as well as older fathers, have been found to have increased incidence of mood disorders (McGrath et al., 2014). Conversely, Fergusson and Woodward (1999) found a significant linear association between increasing maternal age and decreasing rates of anxious and depressive disorders (as per DSM-IV criteria) in 18 year old offspring. Other studies using data from the Western Australian Pregnancy Cohort (Raine) Study have indicated that maternal age is a significant prenatal predictor of risk for child behaviour outcomes from age 2 to 14 (Tearne et al., 2014), and that there is a significant linear association between maternal age and risk for problem internalising and externalising behaviours in children from age 2-17, where older maternal age is associated with decreased risk for child behaviour problems (Tearne et al., 2015).

To our knowledge, there are no studies which examine the incidence of symptoms of depression and anxiety (as opposed to diagnosis with a major depressive or anxious disorder) as a function of parental age in young adults. Furthermore, parental age has not been examined in relation to stress in offspring as far as we are aware. Investigation of these issues is important as it is recognised that mental health 
issues may not always be limited to those who meet criteria for a psychiatric diagnosis. By limiting the focus of study to those who meet diagnostic criteria, the broader spectrum of psychological adjustment and distress is ignored. This study sought to examine the relationship between maternal and paternal age and depression, anxiety and stress symptoms, measured by the short form of the Depression Anxiety Stress Scales (DASS-21) in offspring in a population based cohort of Western Australian young adults, and to build upon previous studies from the Raine cohort examining parental age and mental health outcomes in offspring by considering outcomes in young adults. Given findings that there may be a sexually dimorphic effect of parental age on offspring outcomes in terms of severe mental health outcomes, we also sought to determine whether sex modifies the relationship between parental age and a broader spectrum of mental health outcomes in offspring. In line with previous literature, it was hypothesised that offspring of teenaged mothers and fathers would be at increased risk of elevated DASS-21 scores. The existing findings relating to mood symptoms in offspring and older parents are mixed, and as such we sought to clarify what relationships, if any, existed between older parental age and depression, anxiety and stress in offspring.

\section{Methods}

\section{Study population}

The Raine Study is a population-based prospective pregnancy cohort study. The methodology for the study has been described in detail elsewhere (Newnham, Evans, Michael, Stanley, \& Landau, 1993). Briefly, 2900 pregnant women were recruited to the study between 16 and 20 weeks gestation through the public antenatal clinic at King Edward Memorial Hospital (KEMH) in Perth, Western Australia or 
surrounding private practices between May 1989 and November 1991. The criteria for enrolment into the study were English language proficiency sufficient to understand the implications of participating in the study, an expectation that they would deliver at $\mathrm{KEMH}$, and an intention to remain in Western Australia to facilitate follow up of their child(ren). Ninety percent of eligible women agreed to take part. Participants provided data on psychosocial and sociodemographic characteristics at enrolment and again at 34 weeks' gestation. A total of 2868 live infants and their families have since undergone assessment at ages 1, 2, 3, 5, 8, 10, 14, 17, 20 and 23 years. Written parental and adolescent/young adult consent (y14, 17, 20 and 23) was provided at each follow up. It has been previously reported that the initial Raine sample overrepresented socially disadvantaged families, and that selective attrition of the sample over time led to a closer representation of those in the sample to the Western Australian population (Robinson et al., 2010). The protocols for the study were approved by the Human Research Ethics Committees at KEMH and the Princess Margaret Hospital for Children in Perth, Western Australia. Ethics approval for the 20-year follow up was obtained from the University of Western Australia Human Research Ethics Committee.

\section{Loss to follow up}

Data collection for the 20-year follow up took place between March 2010 and April 2012. There were 2125 young adults eligible for follow up at 20 years. Of the 1565 (74\%) who participated, 78\% $(n=1220)$ completed the DASS-21. Characteristics of those who completed the DASS-21 at follow up compared with those from the original cohort who did not are presented in Table 1. 


\section{Mental health data}

Anxiety, depression and stress were assessed using the short form of the Depression Anxiety Stress Scales (DASS-21) (S. H. Lovibond \& P. F. Lovibond, 1995). The DASS-21 is a short form of the 42-item DASS (S. H. Lovibond \& P. F. Lovibond, 1995) with both scales found to have good reliability and validity in clinical and non-clinical samples (Antony, Bieling, Cox, Enns, \& Swinson, 1998; Crawford \& Henry, 2003; Henry \& Crawford, 2005). The DASS comprises three seven-item scales measuring depression, anxiety, and stress. The depression scale assesses dysphoria, hopelessness, devaluation of life, self-depreciation, lack of interest/involvement, anhedonia and inertia; the anxiety scale measures autonomic arousal, skeletal musculature effects, situational anxiety and subjective experience of anxious affect; and the stress scale assesses difficulty relaxing, nervous arousal, being easily upset/agitated, irritable/over-reactive and impatient (S. H. Lovibond \& P. F. Lovibond, 1995). Participants were asked to rate the severity of each symptom during the past week on a four-point scale ranging from zero (“did not apply to me at all”) to 3 ("applied to me very much, or most of the time”). Scores were doubled as per the scoring instructions.

The depression and anxiety scales of the 42-item DASS show good convergent validity with the Beck Anxiety and Depression Inventories (Lovibond \& Lovibond, 1995). Several studies have suggested temporal stability of the DASS across time (Brown, Chorpita, Korotitsch, \& Barlow, 1997; Cunningham, Brown, Brooks, \& Page, 2013; Page, Hooke, \& Morrison, 2007; Willemsen, Markey, Declercq, \& Vanheule, 2011). A large scale study has shown stability of symptoms as measured by the DASS over 3 to 8 years (Lovibond, 1998). Analyses specific to the DASS-21 have shown a quadripartite structure, which consisted of a general factor 
which the authors suggested reflected general psychological distress, and orthogonal factors suggested to represent depression, anxiety, and stress (Henry \& Crawford, 2005). Whilst there is evidence for a common factor representing shared variance underlying the DASS scales, there is also strong evidence for specific factors underlying the depression, anxiety, and stress subscales. Furthermore, there is extensive evidence in the literature that anxiety and depression are not independent constructs (Clark \& Watson, 1991), and thus evidence for shared variance underlying the DASS subscales provides support for the construct validity of the DASS. As a result, the three subscales were included as the outcome measures in the present study.

\section{Predictor variables}

Parental age and date of birth were recorded at initial recruitment. Both maternal and paternal age in years at birth of the study child were calculated and modelled as continuous and categorical variables. In the case of parental age as a categorical variable, age was stratified into five year age groups (<20, 20-24, 25-29, 30-34, 35-39, $\geq 40$ years of age) but for mothers the older two age categories were collapsed to form one $(\geq 35)$ due to small numbers of women aged 40 and over in the sample. This categorisation is often used in classification of population fertility data and broader epidemiological investigations (Australian Bureau of Statistics, 2010; Buizer-Voskamp et al., 2011). A maternal and paternal age of 25-29 years was set as the reference group in all analyses as the peak fertility rate for Australian women was in this age group at the time of recruitment to the Raine Study (Australian Bureau of Statistics, 2010). 


\section{Control variables}

We adjusted for several prenatal variables previously established as key predictors of mental health outcomes in the Raine cohort (Tearne et al., 2014). These variables included maternal education (12 or more years of education compared with 11 or fewer), maternal smoking during the first 18 weeks of pregnancy (no smoking compared to any smoking), maternal experience of stressful life events in the first 18 weeks of pregnancy (two or fewer compared to three or more), total family income as at 18 weeks of pregnancy $(<24000$ AUD compared to $\geq 24000$ AUD, in accordance with the poverty line at the time of collection) and maternal diagnosis of gestational hypertension (no hypertension compared to any hypertension).

\section{Statistical analyses}

We compared characteristics of participants who completed the DASS-21 at the 20-year follow up with non-participants from the original cohort based on gender, race, maternal education, total family income at 18 weeks' gestation, maternal smoking in the first 18 weeks of pregnancy, maternal experience of stressful life events in the first 18 weeks of pregnancy, gestational hypertension, and maternal and paternal age at birth of study child using Chi-square tests. We examined the skewness of the DASS-21 scales and set skewness $>1$ as an indicator of suitability for nonparametric analysis. All subscales were found to be skewed.

Given the skewness of the DASS-21 subscale scores, we performed negative binomial regression analyses with a log link to investigate the association between maternal and paternal age and DASS-21 scores (depression, anxiety and stress subscale scores). These elicited a rate ratio (RR) which we interpreted as the proportional increase in DASS-21 scores compared to the reference category for the 
categorical models. Several studies report gender based differences in DASS scores (Crawford \& Henry, 2003; Gomez, Summers, Summers, Wolf, \& Summers, 2014). In particular, one study using a non-clinical sample found gender differences in depression and anxiety subscale scores, and on total DASS scores (female scores significantly higher than male) (Crawford \& Henry, 2003). As such, preliminary analyses tested whether sex moderated the association between parental age and mental health outcomes. We initially ran models adjusting only for the age of the other parent, with the subsequent models adjusting for age and known confounding variables as detailed above. Analyses were performed using IBM SPSS Statistics Version 22.

\section{Results}

Characteristics of participants and non-participants from the original cohort are presented in Table 1. In comparison to those from the original cohort who did not take part in the current study $(n=1648)$, those participants who took part in the current study ( $n=1220$ ) were more likely to have older mothers, older fathers, and to have come from families with an income above the poverty line during pregnancy with the study child. Their mothers were more likely to have finished high school, and were less likely to have smoked and experienced stressful life events during pregnancy with the study child. Boys from the original cohort were less likely than girls to participate at age 20. There were no differences based on race or gestational hypertension between participants and non-participants from the original cohort. Given the significant differences between the initial Raine population and those that completed the DASS at the 20-year follow up, inverse probability weighting was used to standardise the sample and adjust for bias that may result from non-random 
attrition. Weights were created using the previously mentioned pregnancy variables, from which a probability of participation and the inverse of this probability were created. Applying these weights created a sample with approximately similar distribution to that of the original Raine cohort.

The internal consistency of the DASS-21 scales was moderate to high $($ Cronbach $\alpha$; Total scale $=.93 ;$ Depression scale $=.89$; Anxiety scale $=.76$; Stress scale $=.86$ ). Median and mean DASS-21 total and subscale scores are presented in Table 2. Mean and median scores in this sample were slightly higher than those reported in another non-clinical sample (Henry \& Crawford, 2005). There were significant differences between male and female scores on all subscales of the DASS21, with females scoring higher. Maternal and paternal age were moderately correlated with each other $(r=.47, p>.01)$.

We initially tested whether there was an interaction between maternal age and offspring gender, and paternal age and offspring gender, and offspring outcomes. There was a significant interaction between maternal age and offspring gender, and paternal age and offspring gender for total DASS scores and all symptom scale scores. As such, all analyses were stratified based on gender (see supplementary information).

In the final multivariate models, where we adjusted for age of other parent and known confounders, a maternal age of 30-34 years was associated with significantly increased stress $(R R=1.27, p=.031)$ subscale scores in female offspring relative to the reference group (Table 3). A maternal age of 35 years and over was associated with increases in all subscale scores in female offspring (Depression: $R R=1.51, p=$ .026; Anxiety: $R R=1.51, p=.029$; Stress: $R R=1.36, p=.033$ ). There was some evidence of an association between a paternal age of 30-34 years and decreased stress 
subscale scores in female offspring $(R R=.80, p=.045)$. No other paternal ages were associated with significantly different risk for DASS subscale scores in female offspring. The relationships between maternal and paternal age and DASS subscale scores are presented in Figures 1-3. There was some evidence that young maternal age was associated with decreased stress scale scores in male offspring $(R R=.63, p=$ .04). No other maternal nor paternal age groups were associated with significantly different DASS subscale scores. Table 4).

\section{Discussion}

Our results suggest that older maternal age is related to an increased risk of depression, anxiety and stress symptoms in young adult females. Paternal age was not found to be related to risk in females, and neither maternal nor paternal age predicted risk of these symptoms in young adult males. These relationships persisted after adjustment for a number of factors known to influence mental health in offspring.

Our results differ from other studies suggesting that older paternal age is linked to increased incidence of mood disorders (Buizer-Voskamp et al., 2011; McGrath et al., 2014), and with a larger body of literature suggesting older paternal age is associated with a range of other adverse psychiatric outcomes in offspring (Hultman et al., 2010; McGrath et al., 2014; Miller et al., 2011). A key difference is that our study examined self-reported symptoms of depression, anxiety and stress rather than clinical diagnoses. It is plausible that the risk factors for psychological adjustment and distress differ from those risk factors identified for more severe psychiatric outcomes. The results of our study suggest that when moving beyond diagnosis to consider a broader spectrum of psychological distress and adjustment in 
offspring, paternal age is not an important factor of influence, at least in this sample when using the DASS-21 as an outcome variable. This is an important finding when placed in the context of the existing literature, because it suggests that father's age may have a differential impact on different types of psychiatric distress/illness, and not be relevant for all outcomes. It is plausible that at the level of distress, rather than disorder, associations with parental age may stem from environmental factors, such as interactions with the parent, rather than biology. It may be the case that the significance of maternal and not paternal age as predictors of offspring outcomes may reflect an imbalance in key relationships in the caregiving of the child, such that maternal age exerts a greater influence because mothers may have played a greater caregiving role. In the few existing studies examining maternal age and mood disorders in offspring, older maternal age has been found to have no significant association with offspring outcome in two studies (Buizer-Voskamp et al., 2011; McGrath et al., 2014), and was associated with decreased risk for depressive and anxious disorders in 18 year old offspring (Fergusson \& Woodward, 1999), and decreased risk for internalising disorders across childhood (Tearne et al., 2015). Our study suggests that maternal age is implicated in the subsequent experience of symptoms of depression, anxiety and stress in female young adult offspring. This is somewhat different from the results presented in the aforementioned studies, although our findings are consistent with a study finding older maternal age may be associated with increased risk for bipolar affective disorder (Menezes et al., 2010). This finding is also broadly consistent with a number of studies suggesting advanced maternal age is associated with increased risk for autism spectrum disorders in offspring (Croen, Najjar, Fireman, \& Grether, 2007; Durkin et al., 2008; Grether, Anderson, Croen, 
Smith, \& Windham, 2009; King, Fountain, Dakhlallah, \& Bearman, 2009; Parner et al., 2012; Sandin et al., 2012)

Future research should attend to uncovering potential mechanisms underlying the relationship between maternal age and depression, anxiety and stress symptoms in female offspring. It is possible that it is not so much age at pregnancy that underpins the relationship between maternal age and symptoms in female offspring, but age of the mother at follow-up assessment (which is an indirect effect of age at pregnancy). One possible hypothesis is difficulties in the mother-daughter relationship due to a large age difference between the two parties. The "older mothers" in our sample were 50-54 and 55 and over when their offspring were 20 years of age. It may be that a 30 or more year age difference between mother and daughter leads to a significant difference in the value systems held by each, as well as generational differences that may cause tension in the relationship, particularly during the transition period of young adulthood, leading to stress, worry and sadness in the child. The increased incidence of depression, anxiety and stress symptoms may reflect a stressful period in the lives of both mother and daughter. Another example of possible age-related differences in mother-daughter relationships is the impact of age-related health changes and problems in mothers. The median age at which women in Australia go through menopause is around 51 years of age (Do et al., 1998). Statistics from the Centre for Disease Control and Prevention suggest that once women enter their fifties, the leading causes of mortality are various cancers, heart disease and chronic respiratory conditions (Centre for Disease Control and Prevention, 2010). It has been found that levels of emotional distress and behavioural problems escalate in adolescents and young adults with an immediate family member with a cancer diagnosis (Sahler et al., 1994), and another study suggested that adolescent female 
offspring are most negatively affected by a parent's diagnosis with serious illness (Osborn, 2007). Thus, the higher risk of depression, anxiety and stress in offspring of women in their fifties may be due to health-related stress and concern within the family. It may be that significant life changes are occurring in parallel in mothers and daughters, which may influence emotion dysregulation in offspring.

Another possible explanation for our results is that the relationship between advancing maternal age and offspring mental health outcomes observed in this study may be due to unmeasured confounding. Examining the relationship between maternal age and offspring mental health outcomes is complex, owing to the great number of variables associated with older motherhood that may also exert an influence on offspring outcomes. The statistical position taken in this study was that variables measured at the same time as the key outcome variables (i.e., prenatal variables) were considered as potential confounders, and our large sample size allowed for an exhaustive list of control variables to eliminate, as far as possible, confounding. However, there are myriad other factors that may influence the mental health of offspring. Recent studies in the area using quasi-experimental designs to control for environmental and genetic influences that vary within families using sibling-comparison analyses have yielded interesting findings. One study indicated that environmental factors associated with maternal age at childbirth which also vary within families are implicated in the incidence of delinquent behaviours in offspring (D’Onofrio et al., 2009), whilst another indicated that controlling for variables shared within families strengthened the association between advanced paternal age and various indices of psychopathology, consistent with a causal hypothesis (D’Onofrio et al., 2014). Although beyond this scope of this study, future research designs controlling for factors shared within families may leave researchers better placed to 
identify the specific factors, be they genetic, environmental, or both, that influence offspring behaviour. This would allow us to better specify how maternal age may influence depression, anxiety and stress symptoms in young adult offspring, and why this relationship may be specific to female offspring.

There are a number of strengths associated with this study. Our prospectively collected data are drawn from a large cohort study, allowing us the opportunity for a comprehensive assessment of the impact of parental age on anxiety, stress and depression symptoms in offspring in a non-clinical population. However, our findings must be interpreted in the context of a number of limitations. Firstly, a limitation is our use of self-report data. Self-report measures have been validated as a valid means of assessing depression, anxiety and stress (Antony et al., 1998). Whilst we did not set out to measure clinical levels of distress, but rather more general symptoms of distress in our sample, we cannot rule out the possibility of over- or under-reporting. A second limitation is the relatively small numbers of parents in the oldest (aged 40 and over) and youngest (19 and under) age groups at childbirth in our sample (2.3\% and 9.7\% respectively). This may have impacted upon the strength of the influence of parental age upon offspring in these categories. Further, the DASS-21 data measure symptoms over the past week. Whilst a study using the longer version of the DASS scale has shown stability of each of the syndromes over substantial periods of time (three to eight years), future research could look to investigate the stability of symptoms over time in the Raine and similar cohorts. Another consideration was that it was not possible to differentiate between parental age at birth of first child versus birth of the study child. It has been suggested it may be parental age at birth of first child, not birth of the individual child, which predicts mental health outcomes in offspring (Petersen, 2011). An investigation of this type was beyond the scope of this study, but 
is a worthy focus of future research. Finally, we controlled for a comprehensive range of other prenatal variables known to impact upon mental health in offspring, but this list is not exhaustive and does not take into account the myriad other influences on mental health across the lifespan. For example, family structure was not accounted for in this study. Many variables of interest, such as maternal mental health at follow-up, were not available to us. These variables may impact upon the relationships observed in the data, and further research is necessary to evaluate their impact. Despite these limitations, our data provide new insights into the impact of parental age on general symptoms of anxiety, depression and stress in young adult offspring.

\section{Conclusions}

We found that a maternal age of 30-34 years was associated with significant increases in total DASS-21 scores in female offspring, and a maternal age of 35 years and over was associated with significant increases in total and subscale DASS-21 scores. Paternal age was not found to be associated with offspring depression, anxiety and stress. It would appear that when examining a broad spectrum of psychological adjustment, the relationships between parental age and offspring symptomatology differ from those in the literature on parental age and severe psychiatric outcomes. We suggest that maternal age when the young adult is assessed may be as important as considering age at pregnancy.

\section{Acknowledgements}

JT was supported by a University of Western Australia Completion Scholarship. MR is supported by a NHMRC Early Career Fellowship. The authors acknowledge the 
funding and support of the Raine Medical Research Foundation, The University of Western Australia (UWA), the Telethon Kids Institute, the UWA Faculty of Medicine, Dentistry and Health Sciences, the Women and Infants Research Foundation, and Curtin University of Technology. We acknowledge the long term support and funding from the National Health and Medical Research Council (NHMRC) of Australia and the Raine Medical Research Foundation. The authors are extremely grateful to all the Raine Study participants and their families who took part in this study, as well as the Raine Study team for their cohort coordination and data collection. 


\section{References}

Antony, M. M., Bieling, P. J., Cox, B. J., Enns, M. W., \& Swinson, R. P. (1998). Psychometric Properties of the 42-Item and 21-Item Versions of the Depression Anxiety Stress Scales in Clinical Groups and a Community Sample. Psychological Assessment, 10(2), 176-181.

Australian Bureau of Statistics. (2010). One for the country: Recent trends in fertility. Australian Social Trends. Canberra, Australia,.

Brown, T. A., Chorpita, B. F., Korotitsch, W., \& Barlow, D. H. (1997). Psychometric properties of the Depression Anxiety Stress Scales (DASS) in clinical samples. Behaviour research and therapy, 35(1), 79-89.

Buizer-Voskamp, J. E., Laan, W., Staal, W. G., Hennekam, E. A., Aukes, M. F., Termorshuizen, F., . . . Ophoff, R. A. (2011). Paternal age and psychiatric disorders: findings from a Dutch population registry. Schizophrenia research, 129(2), 128-132.

Byrne, M., Agerbo, E., Ewald, H., Eaton, W. W., \& Mortensen, P. B. (2003). Parental age and risk of schizophrenia: a case-control study. Archives of general psychiatry, 60(7), 673-678.

Centre for Disease Control and Prevention. (2010). Leading Causes of Death in Females. http://www.cdc.gov/nchs/deaths.htm.

Clark, L. A., \& Watson, D. (1991). Tripartite model of anxiety and depression: psychometric evidence and taxonomic implications. Journal of abnormal psychology, 100(3), 316.

Crawford, J. R., \& Henry, J. D. (2003). The Depression Anxiety Stress Scales (DASS): Normative data and latent structure in a large non-clinical sample. British Journal of Clinical Psychology, 42(2), 111-131. 
Croen, L. A., Najjar, D. V., Fireman, B., \& Grether, J. K. (2007). Maternal and paternal age and risk of autism spectrum disorders. Archives of pediatrics \& adolescent medicine, 161(4), 334-340.

Cunningham, N. K., Brown, P. M., Brooks, J., \& Page, A. C. (2013). The structure of emotional symptoms in the postpartum period: Is it unique? Journal of affective disorders, 151(2), 686-694.

D’Onofrio, B. M., Goodnight, J. A., Van Hulle, C. A., Rodgers, J. L., Rathouz, P. J., Waldman, I. D., \& Lahey, B. B. (2009). Maternal age at childbirth and offspring disruptive behaviors: Testing the causal hypothesis. Journal of Child Psychology and Psychiatry, 50(8), 1018-1028.

D’Onofrio, B. M., Rickert, M. E., Frans, E., Kuja-Halkola, R., Almqvist, C., Sjölander, A., . . . Lichtenstein, P. (2014). Paternal age at childbearing and offspring psychiatric and academic morbidity. JAMA psychiatry, 71(4), 432438.

Do, K.-A., Treloar, S. A., Pandeya, N., Purdie, D., Green, A. C., Heath, A. C., \& Martin, N. G. (1998). Predictive Factors of Age at Menopause in a Large Australian Twin Study. Human Biology, 70(6), 1073-1091. doi: $10.2307 / 41465703$

Durkin, M. S., Maenner, M. J., Newschaffer, C. J., Lee, L.-C., Cunniff, C. M., Daniels, J. L., . . Z Zahorodny, W. (2008). Advanced parental age and the risk of autism spectrum disorder. American Journal of Epidemiology, 168(11), 1268-1276.

Fergusson, D. M., \& Woodward, L. J. (1999). Maternal Age and Educational and Psychosocial Outcomes in Early Adulthood. Journal of Child Psychology and Psychiatry, 40(3), 479-489. doi: 10.1111/1469-7610.00464 
Frans, E. M., Sandin, S., Reichenberg, A., Lichtenstein, P., Langstrom, N., \& Hultman, C. M. (2008). Advancing paternal age and bipolar disorder. Archives of general psychiatry, 65(9), 1034-1040.

Gomez, R., Summers, M., Summers, A., Wolf, A., \& Summers, J. (2014). Depression Anxiety Stress Scales-21: Measurement and Structural Invariance Across Ratings of Men and Women. Assessment. doi: 10.1177/1073191113514106

Grether, J. K., Anderson, M. C., Croen, L. A., Smith, D., \& Windham, G. C. (2009). Risk of autism and increasing maternal and paternal age in a large north American population. American Journal of Epidemiology, 170(9), 1118-1126.

Harden, K. P., Lynch, S. K., Turkheimer, E., Emery, R. E., D’Onofrio, B. M., Slutske, W. S., . . Martin, N. G. (2007). A behavior genetic investigation of adolescent motherhood and offspring mental health problems. Journal of Abnormal Psychology, 116(4), 667-683.

Henry, J. D., \& Crawford, J. R. (2005). The short-form version of the Depression Anxiety Stress Scales (DASS-21): Construct validity and normative data in a large non-clinical sample. British Journal of Clinical Psychology, 44(2), 227239.

Hultman, C., Sandin, S., Levine, S., Lichtenstein, P., \& Reichenberg, A. (2010). Advancing paternal age and risk of autism: new evidence from a populationbased study and a meta-analysis of epidemiological studies. Molecular psychiatry, 16(12), 1203-1212.

King, M. D., Fountain, C., Dakhlallah, D., \& Bearman, P. S. (2009). Estimated autism risk and older reproductive age. American Journal of Public Health, 99(9), 1673. 
Lovibond, P. F. (1998). Long-term stability of depression, anxiety, and stress syndromes. Journal of Abnormal Psychology, 107(3), 520-526.

Lovibond, P. F., \& Lovibond, S. H. (1995). The structure of negative emotional states: Comparison of the Depression Anxiety Stress Scales (DASS) with the Beck Depression and Anxiety Inventories. Behaviour research and therapy, 33(3), 335-343.

Lovibond, S. H., \& Lovibond, P. F. (1995). Manual for the depression anxiety stress scales. Psychology Foundation of Australia, Sydney.

McGrath, J. J., Petersen, L., Agerbo, E., Mors, O., Mortensen, P. B., \& Pedersen, C. B. (2014). A comprehensive assessment of parental age and psychiatric disorders. JAMA psychiatry, 71, 301-309.

Menezes, P., Lewis, G., Rasmussen, F., Zammit, S., Sipos, A., Harrison, G., . . . Gunnell, D. (2010). Paternal and maternal ages at conception and risk of bipolar affective disorder in their offspring. Psychological medicine, 40(3), 477-485.

Miller, B., Messias, E., Miettunen, J., Alaräisänen, A., Järvelin, M.-R., Koponen, H., . . . Kirkpatrick, B. (2011). Meta-analysis of paternal age and schizophrenia risk in male versus female offspring. Schizophrenia bulletin, 37(5), 1039-1047.

Newnham, J. P., Evans, S. F., Michael, C. A., Stanley, F. J., \& Landau, L. I. (1993). Effects of frequent ultrasound during pregnancy: a randomised controlled trial. The lancet, 342(8876), 887-891. doi: http://dx.doi.org/10.1016/01406736(93)91944-H

Osborn, T. (2007). The psychosocial impact of parental cancer on children and adolescents: a systematic review. Psycho-Oncology, 16(2), 101-126. 
Page, A. C., Hooke, G. R., \& Morrison, D. L. (2007). Psychometric properties of the Depression Anxiety Stress Scales (DASS) in depressed clinical samples. British Journal of Clinical Psychology, 46(3), 283-297.

Parner, E. T., Baron-Cohen, S., Lauritsen, M. B., Jørgensen, M., Schieve, L. A., Yeargin-Allsopp, M., \& Obel, C. (2012). Parental age and autism spectrum disorders. Annals of epidemiology, 22(3), 143-150.

Robinson, M., Oddy, W. H., McLean, N. J., Jacoby, P., Pennell, C. E., de Klerk, N. H., . . . Newnham, J. P. (2010). Low-moderate prenatal alcohol exposure and risk to child behavioural development: a prospective cohort study. BJOG: An International Journal of Obstetrics \& Gynaecology, 117(9), 1139-1152. doi: 10.1111/j.1471-0528.2010.02596.x

Sahler, O. J., Roghmann, K. J., Carpenter, P. J., Mulhern, R. K., Dolgin, M. J., Sargent, J. R., . . Z Zeltzer, L. K. (1994). Sibling Adaptation to Childhood Cancer Collaborative Study: Prevalence of Sibling Distress and Definition of Adaptation Levels. Journal of Developmental \& Behavioral Pediatrics, 15(5), 353-366.

Sandin, S., Hultman, C. M., Kolevzon, A., Gross, R., MacCabe, J. H., \& Reichenberg, A. (2012). Advancing maternal age is associated with increasing risk for autism: a review and meta-analysis. Journal of the American Academy of Child \& Adolescent Psychiatry, 51(5), 477-486. e471.

Tearne, J. E., Allen, K. L., Herbison, C. E., Lawrence, D., Whitehouse, A. J. O., Sawyer, M. G., \& Robinson, M. (2014). The association between prenatal environment and children's mental health trajectories from 2-14 years. European Child and Adolescent Psychiatry. doi: 10.1007/s00787-014-0651-7 
Tearne, J. E., Robinson, M., Jacoby, P., Li, J., Newnham, J. P., \& McLean, N. J. (2015). Does late childbearing increase the risk for behavioural problems in children? A longitudinal cohort study. Paediatric and Perinatal Epidemiology, 29(1), 41-49. doi: 10.1111/ppe.12165

Willemsen, J., Markey, S., Declercq, F., \& Vanheule, S. (2011). Negative emotionality in a large community sample of adolescents: the factor structure and measurement invariance of the short version of the depression anxiety stress scales (DASS-21). Stress and Health, 27(3), e120-e128. 
Table 1. Characteristics of participants and non-participants from the original cohort.

\begin{tabular}{|c|c|c|c|}
\hline & $\begin{array}{c}\text { Participants } \\
N=1220 \\
n(\%)\end{array}$ & $\begin{array}{c}\text { Non-participants } \\
N=1648 \\
n(\%)\end{array}$ & $p$ \\
\hline Sex & & & $<.001^{*}$ \\
\hline $\mathrm{F}$ & $651(53.4)$ & $762(46.2)$ & \\
\hline M & $569(46.6)$ & 886 (53.8) & \\
\hline Missing & $0(0)$ & $0(0)$ & \\
\hline Race & & & .087 \\
\hline Caucasian & $1064(87.2)$ & 1409 (85.5) & \\
\hline Non-Caucasian & $126(10.3)$ & $205(12.4)$ & \\
\hline Missing & $30(2.5)$ & $34(2.1)$ & \\
\hline Maternal education & & & $<.001^{*}$ \\
\hline 12 or more years & $582(47.7)$ & $513(31.1)$ & \\
\hline 11 or fewer years & 608 (49.8) & $1101(66.8)$ & \\
\hline Missing & $30(2.5)$ & $34(2.1)$ & \\
\hline Income & & & $<.001^{*}$ \\
\hline$\geq 24000$ AUD per annum & 767 (62.9) & $716(43.4)$ & \\
\hline$<24000$ AUD per annum & $423(34.7)$ & 898 (54.5) & \\
\hline Missing & $30(2.5)$ & $34(2.1)$ & \\
\hline Maternal smoking in pregnancy & & & $<.001^{*}$ \\
\hline No smoking & 957 (78.4) & $1091(66.2)$ & \\
\hline Any smoking & $233(19.1)$ & $523(31.7)$ & \\
\hline Missing & $30(2.5)$ & $34(2.1)$ & \\
\hline $\begin{array}{l}\text { Maternal experience of stressful } \\
\text { life events }\end{array}$ & & & $.015^{*}$ \\
\hline 2 or fewer & $1039(85.2)$ & $1356(82.3)$ & \\
\hline 3 or more & $151(12.4)$ & 258 (15.7) & \\
\hline Missing & $30(2.5)$ & $34(2.1)$ & \\
\hline Gestational hypertension & & & .421 \\
\hline No hypertension & 890 (73.0) & $1188(72.1)$ & \\
\hline Any hypertension & 296 (24.3) & 424 (25.7) & \\
\hline Missing & $34(2.8)$ & $36(2.2)$ & \\
\hline $\begin{array}{l}\text { Maternal age at birth of study } \\
\text { child }\end{array}$ & & & $<.001^{*}$ \\
\hline
\end{tabular}




\begin{tabular}{lcc}
$<20$ & $64(5.2)$ & $214(13.0)$ \\
$20-24$ & $209(17.1)$ & $396(24.0)$ \\
$25-29$ & $350(28.7)$ & $495(30.0)$ \\
$30-34$ & $358(29.3)$ & $353(21.4)$ \\
$35-39$ & $175(14.3)$ & $125(7.6)$ \\
$\geq 40$ & $34(2.8)$ & $31(1.9)$ \\
Missing & $30(2.5)$ & $34(2.1)$ \\
\hline Paternal age at birth of study & & \\
child & & \\
$<20$ & $24(2.0)$ & $100(6.1)$ \\
$20-24$ & $150(12.3)$ & $307(18.6)$ \\
$25-29$ & $292(23.9)$ & $461(28.0)$ \\
$30-34$ & $394(32.3)$ & $389(23.6)$ \\
$35-39$ & $202(16.6)$ & $194(11.8)$ \\
$\geq 40$ & $128(10.5)$ & $163(9.9)$ \\
Missing & $30(2.5)$ & $34(2.1)$ \\
\hline
\end{tabular}


Table 2. Median, mean (SD) DASS total and subscales scores for females and males.

\begin{tabular}{lccc}
\hline \multicolumn{1}{c}{ Females } & Males & \\
\hline & Median, Mean (SD) & Median, Mean (SD) & $p$ \\
\hline Depression Scale & $6.00,7.97(8.43)$ & $4.00,6.22(7.43)$ & $.004^{* *}$ \\
Anxiety Scale & $4.00,5.85(6.48)$ & $2.00,4.32(4.74)$ & $<.001^{* * *}$ \\
Stress Scale & $8.00,10.52(8.64)$ & $6.00,7.46(7.21)$ & $<.001^{* * *}$ \\
\hline *** significant at $p<.001,{ }^{* *}$ significant at $p<.01$
\end{tabular}


Table 3. Adjusted analyses estimating the effect of maternal and paternal age on total DASS scores and depression, anxiety and stress subscale scores in girls.

\begin{tabular}{|c|c|c|c|}
\hline & $\begin{array}{c}\text { Depression Scale } \\
\text { RR } \\
(95 \% \mathrm{CI})\end{array}$ & $\begin{array}{c}\text { Anxiety Scale } \\
\text { RR } \\
\text { (95\% CI) }\end{array}$ & $\begin{array}{c}\text { Stress Scale } \\
\text { RR } \\
(95 \% \mathrm{CI})\end{array}$ \\
\hline \multicolumn{4}{|c|}{ Maternal age } \\
\hline $\begin{array}{c}<20 \\
(n=42)\end{array}$ & $\begin{array}{c}\mathrm{RR}=1.41^{*} \\
(.94,2.11)\end{array}$ & $\begin{array}{l}\mathrm{RR}=1.17 \\
(.78,1.74)\end{array}$ & $\begin{array}{l}\mathrm{RR}=1.14 \\
(.84,1.55)\end{array}$ \\
\hline $\begin{array}{c}20-24 \\
(n=100)\end{array}$ & $\begin{array}{l}\mathrm{RR}=1.08 \\
(.79,1.48)\end{array}$ & $\begin{array}{l}\mathrm{RR}=1.17 \\
(.85,1.60)\end{array}$ & $\begin{array}{l}\mathrm{RR}=1.01 \\
(.80,1.29)\end{array}$ \\
\hline $\begin{array}{c}25-29 \\
(n=183)\end{array}$ & Ref. & Ref. & Ref. \\
\hline $\begin{array}{c}30-34 \\
(n=200)\end{array}$ & $\begin{array}{l}\mathrm{RR}=1.27 \\
(.96,1.67)\end{array}$ & $\begin{array}{l}\mathrm{RR}=1.19 \\
(.91,1.57)\end{array}$ & $\begin{array}{l}\mathrm{RR}=1.27 * \\
(1.02,1.57)\end{array}$ \\
\hline $\begin{array}{c}\geq 35 \\
(n=111)\end{array}$ & $\begin{array}{c}\mathrm{RR}=1.51 \\
(1.05,2.16)\end{array}$ & $\begin{array}{l}\mathrm{RR}=1.51^{*} \\
(1.04,2.18)\end{array}$ & $\begin{array}{l}\mathrm{RR}=1.36^{*} \\
(1.03,1.81)\end{array}$ \\
\hline \multicolumn{4}{|l|}{ Paternal age } \\
\hline $\begin{array}{c}<20 \\
(n=15)\end{array}$ & $\begin{array}{l}\mathrm{RR}=.96 \\
(.55,1.69)\end{array}$ & $\begin{array}{l}\mathrm{RR}=.72 \\
(.41,1.29)\end{array}$ & $\begin{array}{l}\mathrm{RR}=1.17 \\
(.75,1.82)\end{array}$ \\
\hline $\begin{array}{c}20-24 \\
(n=81)\end{array}$ & $\begin{array}{l}\mathrm{RR}=1.02 \\
(.73,1.42)\end{array}$ & $\begin{array}{l}\mathrm{RR}=1.06 \\
(.76,1.49)\end{array}$ & $\begin{array}{l}\mathrm{RR}=1.08 \\
(.83,1.39)\end{array}$ \\
\hline $\begin{array}{c}25-29 \\
(n=150)\end{array}$ & Ref. & Ref. & Ref. \\
\hline $\begin{array}{c}30-34 \\
(n=216)\end{array}$ & $\begin{array}{c}\mathrm{RR}=.82 \\
(.63,1.07)\end{array}$ & $\begin{array}{c}\mathrm{RR}=.93 \\
(.71,1.23)\end{array}$ & $\begin{array}{l}\mathrm{RR}=.80^{*} \\
(.65, .995)\end{array}$ \\
\hline $\begin{array}{c}35-39 \\
(n=108)\end{array}$ & $\begin{array}{l}\mathrm{RR}=.87 \\
(.62,1.22)\end{array}$ & $\begin{array}{l}\mathrm{RR}=.99 \\
(.70,1.40)\end{array}$ & $\begin{array}{c}\mathrm{RR}=.86 \\
(.65,1.12)\end{array}$ \\
\hline $\begin{array}{c}\geq 40 \\
(n=66)\end{array}$ & $\begin{array}{l}\mathrm{RR}=1.01 \\
(.67,1.53)\end{array}$ & $\begin{array}{c}\mathrm{RR}=.92 \\
(.60,1.41)\end{array}$ & $\begin{array}{c}\mathrm{RR}=.95 \\
(.68,1.31)\end{array}$ \\
\hline
\end{tabular}

Adjusted for age of other parent, maternal smoking in pregnancy, maternal education, total family income, maternal experience of stressful life events, and maternal gestational hypertension.

$\mathbf{R R}=$ Rate ratio; $=\boldsymbol{p}<.05$

$n=$ number of offspring in each age bin. 
Table 4. Adjusted analyses estimating the effect of maternal and paternal age on total DASS scores and depression, anxiety and stress subscale scores in boys.

\begin{tabular}{|c|c|c|c|}
\hline & $\begin{array}{c}\text { Depression Scale } \\
\text { RR } \\
(95 \% \mathrm{CI})\end{array}$ & $\begin{array}{c}\text { Anxiety Scale } \\
\text { RR } \\
(95 \% \mathrm{CI})\end{array}$ & $\begin{array}{c}\text { Stress Scale } \\
\text { RR } \\
(95 \% \mathrm{CI})\end{array}$ \\
\hline \multicolumn{4}{|c|}{ Maternal age } \\
\hline $\begin{array}{c}<20 \\
(n=22)\end{array}$ & $\begin{array}{l}\mathrm{RR}=.71 \\
(.44,1.15)\end{array}$ & $\begin{array}{l}\mathrm{RR}=.68 \\
(.44,1.05)\end{array}$ & $\begin{array}{c}\mathrm{RR}=.63 * \\
(.41, .98)\end{array}$ \\
\hline $\begin{array}{c}20-24 \\
(n=109)\end{array}$ & $\begin{array}{l}\mathrm{RR}=.77 \\
(.55,1.07)\end{array}$ & $\begin{array}{l}\mathrm{RR}=.87 \\
(.65,1.16)\end{array}$ & $\begin{array}{l}\mathrm{RR}=.80 \\
(.61,1.06)\end{array}$ \\
\hline $\begin{array}{c}25-29 \\
(n=167)\end{array}$ & Ref. & Ref. & Ref. \\
\hline $\begin{array}{c}30-34 \\
(n=158)\end{array}$ & $\begin{array}{l}\mathrm{RR}=1.01 \\
(.74,1.37)\end{array}$ & $\begin{array}{l}\mathrm{RR}=1.07 \\
(.82,1.41)\end{array}$ & $\begin{array}{l}\mathrm{RR}=1.03 \\
(.79,1.33)\end{array}$ \\
\hline $\begin{array}{c}\geq 35 \\
(n=98)\end{array}$ & $\begin{array}{l}\mathrm{RR}=.97 \\
(.65,1.46)\end{array}$ & $\begin{array}{c}\mathrm{RR}=.92 \\
(.65,1.32)\end{array}$ & $\begin{array}{l}\mathrm{RR}=.90 \\
(.63,1.28)\end{array}$ \\
\hline \multicolumn{4}{|l|}{ Paternal age } \\
\hline $\begin{array}{c}<20 \\
(n=9)\end{array}$ & $\begin{array}{c}\mathrm{RR}=.53 \\
(.25,1.17)\end{array}$ & $\begin{array}{l}\mathrm{RR}=.97 \\
(.51,1.85)\end{array}$ & $\begin{array}{c}\mathrm{RR}=.77 \\
(.41,1.45)\end{array}$ \\
\hline $\begin{array}{c}20-24 \\
(n=60)\end{array}$ & $\begin{array}{l}\mathrm{RR}=.98 \\
(.67,1.43)\end{array}$ & $\begin{array}{c}\mathrm{RR}=.94 \\
(.68,1.29)\end{array}$ & $\begin{array}{c}\mathrm{RR}=.98 \\
(.72,1.34)\end{array}$ \\
\hline $\begin{array}{c}25-29 \\
(n=142)\end{array}$ & Ref. & Ref. & Ref. \\
\hline $\begin{array}{c}30-34 \\
(n=178)\end{array}$ & $\begin{array}{l}\mathrm{RR}=1.11 \\
(.83,1.49)\end{array}$ & $\begin{array}{c}\mathrm{RR}=.97 \\
(.75,1.25)\end{array}$ & $\begin{array}{l}\mathrm{RR}=1.01 \\
(.79,1.29)\end{array}$ \\
\hline $\begin{array}{c}35-39 \\
(n=94)\end{array}$ & $\begin{array}{c}\mathrm{RR}=.98 \\
(.65,1.46)\end{array}$ & $\begin{array}{l}\mathrm{RR}=.86 \\
(.60,1.23)\end{array}$ & $\begin{array}{l}\mathrm{RR}=.95 \\
(.67,1.34)\end{array}$ \\
\hline $\begin{array}{c}\geq 40 \\
(n=62)\end{array}$ & $\begin{array}{l}\mathrm{RR}=1.06 \\
(.69,1.64)\end{array}$ & $\begin{array}{l}\mathrm{RR}=1.15 \\
(.80,1.67)\end{array}$ & $\begin{array}{l}\mathrm{RR}=1.23 \\
(.85,1.77)\end{array}$ \\
\hline
\end{tabular}

Adjusted for age of other parent, maternal smoking in pregnancy, maternal education, total family income, maternal experience of stressful life events, and maternal gestational hypertension.

$\mathbf{R R}=$ Rate ratio $=p<.05$

$n=$ number of offspring in each age bin. 